\title{
Existence and Positivity of Solutions for a Second-Order Boundary Value Problem with Integral Condition
}

\author{
Assia Guezane-Lakoud, ${ }^{1}$ Hamidane Nacira, ${ }^{1}$ and Khaldi Rabah ${ }^{2}$ \\ ${ }^{1}$ Laboratory of Advanced Materials, Faculty of Sciences, Badji Mokhtar-Annaba University, \\ P.O. Box 12, 23000 Annaba, Algeria \\ ${ }^{2}$ Laboratory LASEA, Faculty of Sciences, Badji Mokhtar-Annaba University, \\ P.O. Box 12, 23000 Annaba, Algeria
}

Correspondence should be addressed to Hamidane Nacira, nhamidane@yahoo.com

Received 14 January 2012; Accepted 23 February 2012

Academic Editor: Yuji Liu

Copyright (C) 2012 Assia Guezane-Lakoud et al. This is an open access article distributed under the Creative Commons Attribution License, which permits unrestricted use, distribution, and reproduction in any medium, provided the original work is properly cited.

This work is devoted to the study of uniqueness and existence of positive solutions for a secondorder boundary value problem with integral condition. The arguments are based on Banach contraction principle, Leray Schauder nonlinear alternative, and Guo-Krasnosel'skii fixed point theorem in cone. Two examples are also given to illustrate the main results.

\section{Introduction}

Boundary value problem with integral boundary conditions is a mathematical model for of various phenomena of physics, ecology, biology, chemistry, and so forth. Integral conditions come up when values of the function on the boundary are connected to values inside the domain or when direct measurements on the boundary are not possible. The presence of an integral term in the boundary condition leads to great difficulties. Our aim, in this work, is the study of existence, uniqueness, and positivity of solution for the following second-order boundary value problem:

$$
u^{\prime \prime}+f\left(t, u, u^{\prime}\right)=0, \quad 0<t<1
$$

with boundary conditions of type

$$
u(0)=0, \quad u^{\prime}(1)=\int_{0}^{1} t u(t) d t
$$


where $f:[0,1] \times \mathbb{R}^{2} \rightarrow \mathbb{R}$ is a given function. Using the nonlinear alternative of Leray Schauder, we establish the existence of nontrivial solution of the BVP (1.1)-(1.2), under the condition

$$
|f(t, x, y)| \leq h(t)|x|^{\alpha}+g(t)|y|^{\beta}+k(t), \quad \forall(t, x, y) \in[0,1] \times \mathbb{R}^{2},
$$

where $\alpha, \beta \in \mathbb{R}_{+}$, to prove the uniqueness of solution, we apply Banach contraction principle, by using Guo-Krasnosel'skii fixed point theorem in cone we study the existence of positive solution. As applications, some examples to illustrate our results are given.

Various types of boundary value problems with integral boundary conditions were studied by many authors using different methods see [1-9]. In [2] Benchohra et al. have studied (1.1) with the integral condition $u(0)=0, u(1)=\int_{0}^{1} g(s) u(s) d s$, the authors assumed that the function $f$ depends only on $t$ and $u$ and the condition (1.3) holds for $\alpha \in[0,1[$, so our work is new and more general than [2]. Similar boundary value problems for thirdorder differential equations with one of the following conditions $u(0)=0, u^{\prime \prime}(0)=0, u(1)=$ $\int_{0}^{1} g(s) u(s) d s$, or $u(0)=\int_{0}^{1} g(s) u(s) d s, u^{\prime \prime}(0)=\theta, u(1)=0$, were investigated by Zhao et al. in [6], they established the existence and nonexistence and the multiplicity of positive solutions in ordered Banach spaces basing on fixed point theory in cone. For more knowledge about the nonlocal boundary value problem, we refer to the references [10-17].

This paper is organized as follows. In Section 2, we give some notations, recall some concepts and preparation results. In the third Section, we give two main results, the first result based on Banach contraction principle and the second based nonlinear alternative of Leray-Schauder type. In Section 4, we treat the positivity of solutions with the help of Guo-Krasnosel'skii fixed point theorem in cone. Some examples are given to demonstrate the application of our main results, ending this paper.

\section{Preliminaries Lemmas and Materials}

In this section, we introduce notations, definitions, and preliminary facts that will be used in the sequel.

Definition 2.1. A mapping defined on a Banach space is completely continuous if it is continuous and maps bounded sets into relatively compact sets.

Theorem 2.2 (Arzela-Ascoli Theorem 1). Let $K \subset \mathbb{R}^{n}$ be a compact set. A subset $F \subset C(K)$ is relatively compact if and only if it is pointwise bounded and equicontinuous, where $C(K)$ denotes the space of all continuous functions on $K$.

Theorem 2.3 (Arzela-Ascoli Theorem 2). If a sequence $\left\{f_{m}\right\}_{1}^{\infty}$ in $C(K)$ is bounded and equicontinuous then it has a uniformly convergent subsequence.

Now we state the nonlinear alternative of Leray-Schauder.

Lemma 2.4 (see [18]). Let $F$ be a Banach space and $\Omega$ a bounded open subset of $F, 0 \in \Omega$. Let $T: \bar{\Omega} \rightarrow F$ be a completely continuous operator. Then, either there exists $x \in \partial \Omega, \lambda>1$ such that $T(x)=\lambda x$, or there exists a fixed point $x^{*} \in \bar{\Omega}$ of $T$. 
Definition 2.5. A function $f:[0,1] \times \mathbb{R}^{2} \rightarrow \mathbb{R}$ is called $L^{1}$-Carathéodory if

(i) the map $t \rightarrow f(t, u, v)$ is measurable for all $u, v \in \mathbb{R}$;

(ii) the map $(u, v) \rightarrow f(t, u, v)$ is continuous on $\mathbb{R}^{2}$ for almost each $t \in[0,1]$;

(iii) for each $r>0$, there exists an $\varphi_{r} \in L^{1}[0,1]$ such that $|f(t, u, v)| \leq \varphi_{r}(t)$ for almost each $t \in[0,1]$ and $|u|+|v| \leq r$.

We recall the definition of positive solution.

Definition 2.6. A function $u$ is called positive solution of (1.1) if $u(t) \geq 0$, for all $t \in[0,1]$.

We expose the well-known Guo-Krasnosel'skii fixed point Theorem on cone [19].

Theorem 2.7. Let $E$ be a Banach space, and let $K \subset E$, be a cone. Assume $\Omega_{1}$ and $\Omega_{2}$ are open subsets of $E$ with $0 \in \Omega_{1}, \overline{\Omega_{1}} \subset \Omega_{2}$ and let

$$
\mathcal{A}: K \cap\left(\overline{\Omega_{2}} \backslash \Omega_{1}\right) \longrightarrow K
$$

be a completely continuous operator such that

(i) $\|\mathcal{A} u\| \leq\|u\|, u \in K \cap \partial \Omega_{1}$, and $\|\mathcal{A} u\| \geq\|u\|, u \in K \cap \partial \Omega_{2}$; or

(ii) $\|\mathcal{A} u\| \geq\|u\|, u \in K \cap \partial \Omega_{1}$, and $\|\mathcal{A} u\| \leq\|u\|, u \in K \cap \partial \Omega_{2}$.

Then $A$ has a fixed point in $K \cap\left(\overline{\Omega_{2}} \backslash \Omega_{1}\right)$.

Throughout this paper, let $E=C^{1}([0,1], \mathbb{R})$, with the norm $\|u\|_{1}=\|u\|+\left\|u^{\prime}\right\|$, where $\|\cdot\|$ denotes the norm in $C([0,1], \mathbb{R})$ defined by $\|u\|=\max _{t \in[0,1]}|u(t)|$. One can obtain the following result.

Lemma 2.8. Let $\delta \in E$, then the solution of the following boundary value problem:

$$
\begin{gathered}
u^{\prime \prime}(t)=-\delta(t), \quad 0<t<1, \\
u(0)=0, \quad u^{\prime}(1)=\int_{0}^{1} t u(t) d t
\end{gathered}
$$

is given by

$$
u(t)=\int_{0}^{1} G(t, s) \delta(s) d s
$$

where

$$
G(t, s)= \begin{cases}s+\frac{s t}{4}\left(3-s^{2}\right), & \text { if } 0 \leq s \leq t \leq 1, \\ t+\frac{s t}{4}\left(3-s^{2}\right), & \text { if } 0 \leq t \leq s \leq 1 .\end{cases}
$$


Proof. Integrating two times the equation $u^{\prime \prime}(t)=-\delta(t)$ from 0 to $t$, one can obtain

$$
u(t)=-\int_{0}^{t}(t-s) \delta(s) d s+C_{1} t+C_{2}
$$

The condition $u(0)=0$ gives $C_{2}=0$. The second condition $u^{\prime}(1)=\int_{0}^{1} t u(t) d t$ implies

$$
C_{1}=\int_{0}^{1} s u(s) d s+\int_{0}^{1} \delta(s) d s
$$

Substituting $C_{1}$ and $C_{2}$ by their values in (2.5) we obtain

$$
u(t)=-\int_{0}^{t}(t-s) \delta(s) d s+t \int_{0}^{1} s u(s) d s+t \int_{0}^{1} \delta(s) d s
$$

Multiplying (2.7) by $t$ then integrating the resultant equality over $[0,1]$ we get

$$
\int_{0}^{1} t u(t) d t=\frac{-1}{4} \int_{0}^{1}(1-s)^{2}(2+s) \delta(s) d s+\frac{1}{2} \int_{0}^{1} \delta(s) d s
$$

Substituting the second term in the right-hand side of (2.7) by (2.8) it yields

$$
u(t)=-\int_{0}^{t}(t-s) \delta(s) d s+\frac{-t}{4} \int_{0}^{1}(1-s)^{2}(2+s) \delta(s) d s+\frac{3 t}{2} \int_{0}^{1} \delta(s) d s,
$$

it is easy to get

$$
\begin{aligned}
u(t)= & \int_{0}^{t}\left[-\frac{t}{4}(1-s)^{2}(2+s)+s+\frac{t}{2}\right] \delta(s) d s \\
& +\int_{t}^{1}\left(-\frac{t}{4}(1-s)^{2}(2+s)+\frac{3 t}{2}\right) \delta(s) d s,
\end{aligned}
$$

that is

$$
u(t)=\int_{0}^{1} G(t, s) \delta(s) d s
$$

where $G(t, s)$ is given by $(2.4)$.

We have the following result which is useful in what follows.

Remark 2.9. The function $G(t, s)$ is continuous, nonnegative and satisfies for any $t, s \in[0,1]$, $\max G(t, s)=3 / 2$. 
International Journal of Differential Equations

\section{Existence and Uniqueness Theorems}

This section deals with the existence and uniqueness of solutions for the problem (1.1)-(1.2).

Theorem 3.1. Suppose that the following hypotheses hold.

(H1) $f$ is an $L^{1}$-Carathéodory function.

(H2) There exist two nonnegative functions $g_{1}, g_{2} \in L^{1}\left([0,1], \mathbb{R}_{+}\right)$such that for all $x, y, \bar{x}$, $\bar{y} \in \mathbb{R}, t \in[0,1]$ one has

$$
|f(t, x, \bar{x})-f(t, y, \bar{y})| \leq g_{1}(t)|x-y|+g_{2}(t)|\bar{x}-\bar{y}|
$$

(H3) $\left\|g_{1}\right\|_{L^{1}}+\left\|g_{2}\right\|_{L^{1}}<1 / 4$.

Then the problem (1.1)-(1.2) has a unique solution in E.

Proof. Transform the problem (1.1)-(1.2) into a fixed point problem. Consider the operator $T: E \rightarrow E$ defined by

$$
T(u)(t)=\int_{0}^{1} G(t, s) f\left(s, u(s), u^{\prime}(s)\right) d s, \quad t \in[0,1] .
$$

From Lemma 2.8, the problem (1.1)-(1.2) has a solution if and only if the operator $T$ has a fixed point in $E$. Let $u, v \in E$, then for each $t \in[0,1]$ we have

$$
|T u(t)-T v(t)| \leq \int_{0}^{1} G(t, s)\left|f\left(s, u(s), u^{\prime}(s)\right) d s-f\left(s, v(s), v^{\prime}(s)\right)\right| d s .
$$

Hypothesis (H2) and Remark 2.9 imply

$$
|T u(t)-T v(t)| \leq \frac{3}{2}\|u-v\|_{1}\left(\left\|g_{1}\right\|_{L^{1}}+\left\|g_{2}\right\|_{L^{1}}\right)
$$

applying hypothesis (H3) to the right-hand side of the above inequality, we obtain

$$
|T u(t)-T v(t)|<\frac{3}{8}\|u-v\|_{1} .
$$

On the other hand we have for any $t \in[0,1]$ :

$$
\begin{aligned}
T^{\prime} u(t)= & -\int_{0}^{t} f\left(s, u(s), u^{\prime}(s)\right) d s \\
& +\int_{0}^{1}\left(-\frac{1}{4}(1-s)^{2}(2+s)+\frac{3}{2}\right) f\left(s, u(s), u^{\prime}(s)\right) d s .
\end{aligned}
$$


Then for $t, s \in[0,1]$ one can write

$$
\begin{aligned}
\left|T^{\prime} u(t)-T^{\prime} v(t)\right| & \leq \frac{5}{2} \int_{0}^{1}\left|f\left(s, u(s), u^{\prime}(s)\right) d s-f\left(s, v(s), v^{\prime}(s)\right) d s\right| d s \\
& \leq \frac{5}{2}\|u-v\|_{1}\left(\left\|g_{1}\right\|_{L^{1}}+\left\|g_{2}\right\|_{L^{1}}\right)
\end{aligned}
$$

Applying hypothesis $\mathrm{H} 3$ again gives

$$
\left|T^{\prime} u(t)-T^{\prime} v(t)\right|<\frac{5}{8}\|u-v\|_{1}
$$

Combining inequalities (3.5) and (3.8) we obtain

$$
\|T u(t)-T v(t)\|_{1}<\|u-v\|_{1}
$$

thus, $T$ is a contraction mapping on E. By applying the well-known Banach's contraction mapping principle we know that the operator $T$ has a unique fixed point on $E$. Therefore, the problem (1.1)-(1.2) has an unique solution.

Theorem 3.2. Suppose that the following hypotheses hold:

(P1) $f$ is an $L^{1}$-Carathéodory function, the map $t \rightarrow f(t, 0,0)$ is continuous and $f(t, 0,0) \neq 0$, for any $t \in[0,1]$;

(P2) There exist three nonnegative functions $h, g, k \in L^{1}\left([0,1], \mathbb{R}_{+}\right)$and $\alpha \geq 0, \beta \geq 0$, such that for all $(t, x, y) \in[0,1] \times \mathbb{R}^{2}$ one has

$$
|f(t, x, y)| \leq h(t)|x|^{\alpha}+g(t)|y|^{\beta}+k(t) .
$$

(P3)

$$
\|h\|_{L^{1}}+\|g\|_{L^{1}}<\frac{1}{8}, \quad\|k\|_{L^{1}}<\frac{1}{8}
$$

Then the BVP (1.1)-(1.2) has at least one nontrivial solution.

Proof. First we show that $T$ is a completely continuous mapping that we will prove in some steps:

(1) $T$ is continuous. In fact, let $\left\{u_{m}\right\}_{1}^{\infty}$ be a convergent sequence in $E$ such that $u_{m} \rightarrow u$, then $u_{m}^{\prime} \rightarrow u^{\prime}$ and for each $t \in[0,1]$ we have

$$
\begin{aligned}
\left|T u_{m}(t)-T u(t)\right| & \leq \frac{3}{2} \int_{0}^{1}\left|f\left(s, u_{m}(s), u_{m}^{\prime}(s)\right) d s-f\left(s, u(s), u^{\prime}(s)\right)\right| d s \\
& \leq \frac{3}{2}\left\|f\left(\cdot, u_{m}(\cdot), u_{m}^{\prime}(s)\right)-f\left(\cdot, u(\cdot), u^{\prime}(\cdot)\right)\right\|_{L^{1}} .
\end{aligned}
$$


On the other hand we have

$$
\begin{aligned}
\left|T^{\prime} u_{m}(t)-T^{\prime} u(t)\right| & \leq \frac{5}{2} \int_{0}^{1}\left|f\left(s, u_{m}(s), u_{m}^{\prime}(s)\right) d s-f\left(s, u(s), u^{\prime}(s)\right)\right| d s \\
& \leq \frac{5}{2}\left\|f\left(\cdot, u_{m}(\cdot), u_{m}^{\prime}(s)\right)-f\left(\cdot, u(\cdot), u^{\prime}(\cdot)\right)\right\|_{L^{1}} .
\end{aligned}
$$

From the above discussion one can write

$$
\left\|T u_{m}-T u\right\|_{1} \leq 4\left\|f\left(\cdot, u_{m}(\cdot), u_{m}^{\prime}(s)\right)-f\left(\cdot, u(\cdot), u^{\prime}(\cdot)\right)\right\|_{L^{1}} \cdot
$$

Due to (P1) $f$ is Cathéodory, then $\left\|T u_{m}-T u\right\|_{1} \rightarrow 0$ as $m \rightarrow \infty$.

(2) $T$ maps bounded sets into bounded sets in $E$, to establish this step we use ArzelaAscoli Theorem. Let $B_{r}=\left\{u \in E:\|u\|_{1} \leq r\right\}$, then from (P2), we have for any $u \in B_{r}$ and $t \in[0,1]$

$$
\begin{gathered}
|T(u)(t)| \leq \int_{0}^{1} G(t, s)\left|f\left(s, u(s), u^{\prime}(s)\right)\right| d s \leq \frac{3}{2}\left(\|h\|_{L^{1}} r^{\alpha}+\|g\|_{L^{1}} r^{\beta}+\|k\|_{L^{1}}\right), \\
\left|T^{\prime}(u)(t)\right| \leq \frac{5}{2} \int_{0}^{1}\left|f\left(s, u(s), u^{\prime}(s)\right)\right| d s \leq \frac{5}{2}\left(\|h\|_{L^{1}} r^{\alpha}+\|g\|_{L^{1}} r^{\beta}+\|k\|_{L^{1}}\right),
\end{gathered}
$$

consequently

$$
\|T(u)\|_{1} \leq 4\left(\|h\|_{L^{1}} r^{\alpha}+\|g\|_{L^{1}} r^{\beta}+\|k\|_{L^{1}}\right)
$$

that implies $T$ maps bounded sets into bounded sets.

(3) $T$ maps bounded sets into equicontinuous sets of $E$. Let $u \in B_{r}$ and $t_{1}, t_{2} \in[0,1]$, $t_{1}<t_{2}$ and $\left|t_{1}-t_{2}\right|<\delta$, then using (P2) it yields

$$
\begin{aligned}
\left|T u\left(t_{1}\right)-T u\left(t_{2}\right)\right| & \leq \int_{0}^{1}\left|G\left(t_{1}, s\right)-G\left(t_{2}, s\right)\right|\left|f\left(s, u(s), u^{\prime}(s)\right)\right| d s \\
& \leq \int_{0}^{1}\left|G\left(t_{1}, s\right)-G\left(t_{2}, s\right)\right|\left(h(s) r^{\alpha}+g(s) r^{\beta}+k(s)\right) d s \\
& \leq \max _{0 \leq s \leq 1}\left|G\left(t_{1}, s\right)-G\left(t_{2}, s\right)\right|\left(\|h\|_{L^{1}} r^{\alpha}+\|g\|_{L^{1}} r^{\beta}+\|k\|_{L^{1}}\right) .
\end{aligned}
$$

In addition, we have

$$
\begin{aligned}
\left|T^{\prime} u\left(t_{1}\right)-T^{\prime} u\left(t_{2}\right)\right| & \leq \int_{t_{1}}^{t_{2}}\left|f\left(s, u(s), u^{\prime}(s)\right)\right| d s \\
& \leq\left(t_{2}-t_{1}\right)\left(\|h\|_{L^{1}} r^{\alpha}+\|g\|_{L^{1}} r^{\beta}+\|k\|_{L^{1}}\right) .
\end{aligned}
$$


Since $G(t, s)$ is continuous, then $\left|T u\left(t_{1}\right)-T u\left(t_{2}\right)\right|$ tend to 0 when $t_{1} \rightarrow t_{2}$, and we have immediately that $\left|T^{\prime} u\left(t_{1}\right)-T^{\prime} u\left(t_{2}\right)\right| \rightarrow 0$, this yields that $T$ is equicontinuous. Then $T$ is completely continuous.

Secondly, we apply the nonlinear alternative of Leray-Schauder to prove the existence of solution. Let us make the following notations:

$$
M=\|h\|_{L^{1}}+\|g\|_{L^{1}}, \quad N=\|k\|_{L^{1}}
$$

Since $f(t, 0,0) \neq 0$, then there exists an interval $[\eta, \tau] \subset[0,1]$ such that $\min _{\eta \leq t \leq r}|f(t, 0,0)|>0$ hence $N>0$. From hypothesis (P3), we know that $M<1 / 8$. Putting $m=M / N$. Setting $\Omega=\left\{u \in E:\|u\|_{1}<1\right\}$ and let $u \in \partial \Omega, \lambda>1$, such that $T u(t)=\lambda u(t)$. Using the same argument that to get (3.16), it yields

$$
\lambda\|u\|_{1}=\|T(u)\|_{1} \leq 4\left(\|h\|_{L^{1}}\|u\|_{1}^{\alpha}+\|g\|_{L^{1}}\|u\|_{1}^{\beta}+\|k\|_{L^{1}}\right)
$$

as $\|u\|_{1}=1$ then $\lambda \leq 4(M+N)$. First, if $m \leq 1$ then $\lambda \leq 8 N<1$, hence $\lambda<1$, this contradicts the fact that $\lambda>1$. By Lemma 2.4 we conclude that $T$ has a fixed point $u^{*} \in \bar{\Omega}$ and then problem (1.1)-(1.2) has a nontrivial solution $u^{*} \in E$.

Second, if $m \geq 1$ then $\lambda \leq 8 M<1$. By arguing as above we complete the proof.

\section{Existence of Positive Solutions}

In this section the existence results for positive solutions for problem (1.1)-(1.2) are presented. We make the following hypotheses:

(Q1) $f(t, u, v)=a(t) f_{1}(u, v)$ where $a \in C\left((0,1), \mathbb{R}_{+}\right)$and $f_{1} \in C\left(\mathbb{R}_{+} \times \mathbb{R}_{,} \mathbb{R}_{+}\right)$;

(Q2) There exists $0<\tau<1$ such that $\int_{\tau}^{1} a(s) f_{1}\left(u(s), u^{\prime}(s)\right) d s>0$.

The following result gives a priori estimates for solutions of problem (1.1)-(1.2).

Lemma 4.1. Assume that hypotheses $(Q 1)-(Q 2)$ hold then

(i) for $t, s \in(0,1)$, one has

$$
\begin{aligned}
& u(t) \leq \frac{3}{2} \int_{0}^{1} a(s) f_{1}\left(u(s), u^{\prime}(s)\right) d s \\
& u^{\prime}(t) \leq \frac{3}{2} \int_{0}^{1} a(s) f_{1}\left(u(s), u^{\prime}(s)\right) d s
\end{aligned}
$$

(ii) for $t, s \in[\tau, 1]$, one has

$$
\begin{aligned}
& u(t) \geq \frac{\tau^{2}\left(3-\tau^{2}\right)}{4} \int_{0}^{1} a(s) f_{1}\left(u(s), u^{\prime}(s)\right) d s, \\
& u^{\prime}(t) \geq \frac{\tau^{2}\left(3-\tau^{2}\right)}{4} \int_{0}^{1} a(s) f_{1}\left(u(s), u^{\prime}(s)\right) d s .
\end{aligned}
$$


Proof. (i) Let $t, s \in(0,1)$, it is easy to check that inequalities in (4.1) hold.

(ii) Let $t, s \in(0,1)$, such that $0<\tau \leq s, t \leq 1$, then

$$
\begin{aligned}
u(t)= & \int_{0}^{t}\left(s+\frac{s t}{4}\left(3-s^{2}\right)\right) a(s) f_{1}\left(u(s), u^{\prime}(s)\right) d s \\
& +\int_{t}^{1}\left(t+\frac{s t}{4}\left(3-s^{2}\right)\right) a(s) f_{1}\left(u(s), u^{\prime}(s)\right) d s \\
\geq & \int_{0}^{1} \frac{s t}{4}\left(3-s^{2}\right) a(s) f_{1}\left(u(s), u^{\prime}(s)\right) d s \\
\geq & \frac{\tau}{4} \int_{0}^{1} s\left(3-s^{2}\right) a(s) f_{1}\left(u(s), u^{\prime}(s)\right) d s \\
\geq & \frac{\tau^{2}\left(3-\tau^{2}\right)}{4} \int_{0}^{1} a(s) f_{1}\left(u(s), u^{\prime}(s)\right) d s,
\end{aligned}
$$

by similar ideas, it yields

$$
\begin{aligned}
u^{\prime}(t)= & \int_{0}^{t}\left(\frac{s}{4}\left(3-s^{2}\right)\right) a(s) f_{1}\left(u(s), u^{\prime}(s)\right) d s \\
& +\int_{t}^{1}\left(1+\frac{s}{4}\left(3-s^{2}\right)\right) a(s) f_{1}\left(u(s), u^{\prime}(s)\right) d s \\
\geq & \int_{0}^{1} \frac{s}{4}\left(3-s^{2}\right) a(s) f_{1}\left(u(s), u^{\prime}(s)\right) d s \\
\geq & \frac{\tau\left(3-\tau^{2}\right)}{4} \int_{\tau}^{1} a(s) f_{1}\left(u(s), u^{\prime}(s)\right) d s \\
\geq & \frac{\tau^{2}\left(3-\tau^{2}\right)}{4} \int_{\tau}^{1} a(s) f_{1}\left(u(s), u^{\prime}(s)\right) d s .
\end{aligned}
$$

The proof is complete.

Lemma 4.2. Assume that hypotheses (Q1)-(Q2) hold, then the solution of the problem (1.1)-(1.2) is positive and satisfies

$$
\min _{t \in[\tau, 1]}\left(u(t)+u^{\prime}(t)\right) \geq\left(\frac{\tau^{2}\left(3-\tau^{2}\right)}{3}\right) r\|u\|_{1}
$$

where $r=\int_{\tau}^{1} a(s) f_{1}(u(s), v(s)) d s / \int_{0}^{1} a(s) f_{1}\left(u(s), u^{\prime}(s)\right) d s$. 
Proof. It follows from Lemma 4.1 that

$$
\begin{aligned}
& \int_{0}^{1} a(s) f_{1}\left(u(s), u^{\prime}(s)\right) d s \geq \frac{2}{3}\|u\| \\
& \int_{0}^{1} a(s) f_{1}\left(u(s), u^{\prime}(s)\right) d s \geq \frac{2}{3}\left\|u^{\prime}\right\| .
\end{aligned}
$$

In view of (4.2) we obtain

$$
u(t) \geq \frac{\tau^{2}\left(3-\tau^{2}\right)}{4} \frac{\int_{\tau}^{1} a(s) f_{1}(u(s), v(s)) d s}{\int_{0}^{1} a(s) f_{1}\left(u(s), u^{\prime}(s)\right) d s} \int_{0}^{1} a(s) f_{1}\left(u(s), u^{\prime}(s)\right) d s,
$$

so,

$$
u(t) \geq\left(\frac{\tau^{2}\left(3-\tau^{2}\right)}{6}\right) \gamma\|u\|
$$

Similarly, one finds

$$
u^{\prime}(t) \geq\left(\frac{\tau^{2}\left(3-\tau^{2}\right)}{6}\right) r\left\|u^{\prime}\right\|
$$

Further, according to inequalities (4.9) and (4.10) we get

$$
\min _{t \in[\tau, 1]}\left(u(t)+u^{\prime}(t)\right) \geq\left(\frac{\tau^{2}\left(3-\tau^{2}\right)}{3}\right) r\|u\|_{1}
$$

ending the proof Lemma 4.2.

Define the quantities $A_{0}$ and $A_{\infty}$ by

$$
A_{0}=\lim _{(|u|+|v|) \rightarrow 0} \frac{f_{1}(u, v)}{|u|+|v|}, \quad A_{\infty}=\lim _{(|u|+|v|) \rightarrow \infty} \frac{f_{1}(u, v)}{|u|+|v|}
$$

The case $A_{0}=0$ and $A_{\infty}=\infty$ is called superlinear case and the case $A_{0}=\infty$ and $A_{\infty}=0$ is called sublinear case. The main result of this section is the following.

Theorem 4.3. Assume that hypotheses (Q1)-(Q2) hold, then problem (1.1)-(1.2) has at least one positive solution in the both cases superlinear as well as sublinear.

To prove this theorem we apply the well-known Guo-Krasnosel'skii fixed point Theorem in cone. 
Proof. Denote $E^{+}=\{u \in E, u(t) \geq 0$, for all $t \in[0,1]\}$ and define the cone $K$ by

$$
K=\left\{u \in E^{+}, \min _{t \in[\tau, 1]}\left(u(t)+u^{\prime}(t)\right) \geq\left(\frac{\tau^{2}\left(3-\tau^{2}\right)}{3}\right) r\|u\|_{1}\right\}
$$

where $\gamma$ is given in Lemma 4.2.

It is easy to check that $K$ is a nonempty closed and convex subset of $E$.

Using Lemma 4.2 we see that $T K \subset K$. Applying Arzela-Ascoli Theorem we know that $T: K \rightarrow E$ is completely continuous for $u \in K$. On the basis of hypothesis (Q1), one can write

$$
T u(t)=\int_{0}^{1} G(t, s) a(s) f_{1}\left(u(s), u^{\prime}(s)\right) d s
$$

Let us consider the superlinear case. Since $A_{0}=0$, then for any $\varepsilon>0$, there exists $R_{1}>0$, such that if $0<|u|+|v| \leq R_{1}$ then $f_{1}(u, v) \leq \varepsilon(|u|+|v|)$. Let $\Omega_{1}=\left\{u \in E,\|u\|_{1}<R_{1}\right\}$, then for any $u \in K \cap \partial \Omega_{1}$, we have

$$
T u(t) \leq \frac{3}{2} \varepsilon\|u\|_{1} \int_{0}^{1} a(s) d s .
$$

Moreover, we obtain

$$
T u^{\prime}(t) \leq \frac{3}{2} \varepsilon\|u\|_{1} \int_{0}^{1} a(s) d s .
$$

By virtue of (4.15) and (4.16) we deduce

$$
\|T u\|_{1} \leq 3 \varepsilon\|u\|_{1} \int_{0}^{1} a(s) d s
$$

Taking hypothesis $\left(\mathrm{Q}_{2}\right)$ into account, one can choose $\varepsilon$ such

$$
\varepsilon \leq \frac{1}{3 \int_{0}^{1} a(s) d s} .
$$

The inequalities (4.17) and (4.18) imply that $\|T u\|_{1} \leq\|u\|_{1}$, for any $u \in K \cap \partial \Omega_{1}$.

Second, since $A_{\infty}=\infty$, then for any $L>0$, there exists $R_{2}>0$, such that $f_{1}(u, v) \geq$ $L(|u|+|v|)$ for $|u|+|v| \geq R_{2}$.

Let $R=\max \left\{2 R_{1}, R_{2} / \delta\right\}$, where $\delta=\tau^{2}\left(3-\tau^{2}\right) \gamma / 3$ and denote by $\Omega_{2}=\left\{u \in E:\|u\|_{1}<\right.$ $R\}$. If $u \in K \cap \partial \Omega_{2}$ then

$$
\min _{t \in[\tau, 1]}\left(u(t)+u^{\prime}(t)\right) \geq\left(\frac{\tau^{2}\left(3-\tau^{2}\right)}{3}\right) r\|u\|_{1}=\delta R \geq R_{2} .
$$


Using similar techniques as in the proof of the second statement of Lemma 4.1 we obtain

$$
T u(t) \geq\left(\frac{\tau^{2}\left(3-\tau^{2}\right)}{3}\right) \int_{\tau}^{1} a(s) f_{1}\left(u(s), u^{\prime}(s)\right) d s
$$

thus

$$
T u(t) \geq\left(\frac{\tau^{2}\left(3-\tau^{2}\right)}{3}\right) L\|u\|_{1} \int_{\tau_{1}}^{1} a(s) d s
$$

moreover,

$$
T^{\prime} u(t) \geq\left(\frac{\tau^{2}\left(3-\tau^{2}\right)}{3}\right) L\|u\|_{1} \int_{\tau_{1}}^{1} a(s) d s
$$

It follows from (4.21) and (4.22) that

$$
T u(t)+T^{\prime} u(t) \geq 2 L\|u\|_{1}\left(\frac{\tau^{2}\left(3-\tau^{2}\right)}{3}\right) \int_{\tau}^{1} a(s) d s
$$

Let us choose $L$ such that

$$
L \geq\left[\left(\frac{2 \tau^{2}\left(3-\tau^{2}\right)}{3}\right) \int_{\tau}^{1} a(s) d s\right]^{-1},
$$

that implies $T u(t)+T^{\prime} u(t) \geq\|u\|_{1}$. Hence,

$$
\|T u\|_{1} \geq\|u\|_{1}, \quad \forall u \in K \cap \partial \Omega_{2}
$$

The first statement of Theorem 2.7 implies that $T$ has a fixed point in $K \cap\left(\overline{\Omega_{2}} \backslash \Omega_{1}\right)$ such that $R_{2} \leq\|u\|_{1} \leq R$. Applying similar techniques as above, we prove the sublinear case. The proof of Theorem 4.3 is complete.

To illustrate the main results, we consider the following examples.

Example 4.4. Consider the following boundary value problem (P1):

$$
\begin{gathered}
u^{\prime \prime}(t)=\frac{u}{2(t+3) \ln (t+3)}+\frac{e^{-t}}{8\left(1+t^{4}\right)} \sin u^{\prime}, \quad t \in(0,1), \\
u(0)=0, \quad u^{\prime}(1)=\int_{0}^{1} t u(t) d t .
\end{gathered}
$$


Choosing $g_{1}(t)=1 / 2(t+3) \ln (t+3), g_{2}(t)=e^{-t} / 8\left(1+t^{4}\right)$, it is easy to see that $\left\|g_{1}\right\|_{L^{1}}+\left\|g_{2}\right\|_{L^{1}} \approx$ $0.185<1 / 4$ and hypotheses $(\mathrm{H} 1)-(\mathrm{H} 3)$ of Theorem 3.1 are satisfied, then, problem (P1) has a unique solution in $E$.

Example 4.5. The following boundary value problem (P2):

$$
\begin{aligned}
u^{\prime \prime}(t)= & \frac{1}{10(t+2)} \ln (t+2) \frac{1+|u(t)|^{1 / 5}}{1+|u(t)|}-\frac{1}{2(3 t+1)^{4}} \frac{\left|u^{\prime}(t)\right|^{4 / 3}}{1+\left|u^{\prime}(t)\right|^{2}} \\
& +\frac{1}{10(t+2)} \ln (t+2), \quad t \in(0,1) \\
u(0) & =0, \quad u^{\prime}(1)=\int_{0}^{1} t u(t) d t
\end{aligned}
$$

has at least one solution in $E$. In fact, we have $\left|f\left(t, u, u^{\prime}\right)\right| \leq h(t)|u(t)|^{1 / 5}+g(t)\left|u^{\prime}(t)\right|^{4 / 3}+k(t)$, where $h(t)=k(t)=(1 / 10(t+2)) \ln (t+2), g(t)=1 / 2(3 t+1)^{4}$, by calculation we obtain $\|h\|_{L^{1}}+\|g\|_{L^{1}} \approx 0,09<1 / 8$ and $\|k\|_{L^{1}}=\int_{0}^{1}(1 / 10(t+2)) \ln (t+2) d t=0.0363<1 / 8$. From Theorem 3.2, we deduce the existence of at least one solution in $E$.

\section{References}

[1] B. Ahmad, A. Alsaedi, and B. S. Alghamdi, "Analytic approximation of solutions of the forced Duffing equation with integral boundary conditions," Nonlinear Analysis, vol. 9, no. 4, pp. 1727-1740, 2008.

[2] M. Benchohra, J. J. Nieto, and A. Ouahab, "Second-order boundary value problem with integral boundary conditions," Boundary Value Problems, vol. 2011, Article ID 260309, 9 pages, 2011.

[3] M. Feng, "Existence of symmetric positive solutions for a boundary value problem with integral boundary conditions," Applied Mathematics Letters, vol. 24, no. 8, pp. 1419-1427, 2011.

[4] M. Feng, B. Du, and W. Ge, "Impulsive boundary value problems with integral boundary conditions and one-dimensional p-Laplacian," Nonlinear Analysis, vol. 70, no. 9, pp. 3119-3126, 2009.

[5] P. Kang, Z. Wei, and J. Xu, "Positive solutions to fourth-order singular boundary value problems with integral boundary conditions in abstract spaces," Applied Mathematics and Computation, vol. 206, no. 1, pp. 245-256, 2008.

[6] J. Zhao, P. Wang, and W. Ge, "Existence and nonexistence of positive solutions for a class of third order BVP with integral boundary conditions in Banach spaces," Communications in Nonlinear Science and Numerical Simulation, vol. 16, no. 1, pp. 402-413, 2011.

[7] X. Zhang, M. Feng, and W. Ge, "Existence result of second-order differential equations with integral boundary conditions at resonance," Journal of Mathematical Analysis and Applications, vol. 353, no. 1, pp. 311-319, 2009.

[8] X. Zhang, M. Feng, and W. Ge, "Symmetric positive solutions for $p$-Laplacian fourth-order differential equations with integral boundary conditions," Journal of Computational and Applied Mathematics, vol. 222, no. 2, pp. 561-573, 2008.

[9] X. Zhang and W. Ge, "Positive solutions for a class of boundary-value problems with integral boundary conditions," Computers \& Mathematics with Applications, vol. 58, no. 2, pp. 203-215, 2009.

[10] M. Feng and W. Ge, "Positive solutions for a class of $m$-point singular boundary value problems," Mathematical and Computer Modelling, vol. 46, no. 3-4, pp. 375-383, 2007.

[11] J. R. Graef, C. Qian, and B. Yang, "A three point boundary value problem for nonlinear fourth order differential equations," Journal of Mathematical Analysis and Applications, vol. 287, no. 1, pp. 217-233, 2003.

[12] A. Guezane-Lakoud and R. Khaldi, "Study of a third-order three-point boundary value problem," in Proceedings of the International Conference on Mathematical Science (ICMS '10), vol. 1309 of AIP Conference Proceedings, pp. 329-335, Bolu, Turkey, November 2010.

[13] A. Guezane-Lakoud and S. Kelaiaia, "Solvability of a nonlinear boundary value problem," The Journal of Nonlinear Science and Applications, vol. 4, no. 4, pp. 247-261, 2011. 
[14] B. Liu, "Positive solutions of fourth-order two point boundary value problems," Applied Mathematics and Computation, vol. 148, no. 2, pp. 407-420, 2004.

[15] R. Ma, "A survey on nonlocal boundary value problems," Applied Mathematics E-Notes, vol. 7, pp. 257-279, 2007.

[16] Y. Sun and L. Liu, "Solvability for a nonlinear second-order three-point boundary value problem," Journal of Mathematical Analysis and Applications, vol. 296, no. 1, pp. 265-275, 2004.

[17] B. Yang, "Positive solutions for a fourth order boundary value problem," Electronic Journal of Qualitative Theory of Differential Equations, no. 3, p. 17, 2005.

[18] K. Deimling, Non-linear Functional Analysis, Springer, Berlin, Germany, 1985.

[19] D. Guo and V. Lakshmikantham, Nonlinear Problems in Abstract Cones, Academic Press, San Diego, Calif, USA, 1988. 


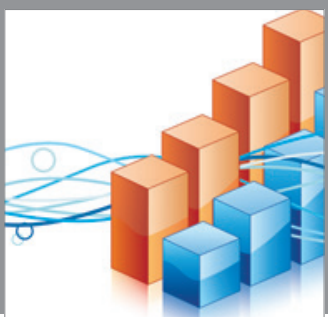

Advances in

Operations Research

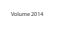

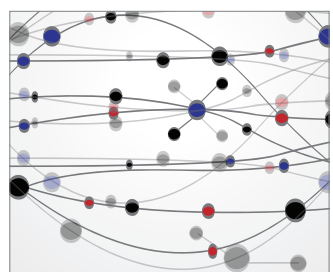

\section{The Scientific} World Journal
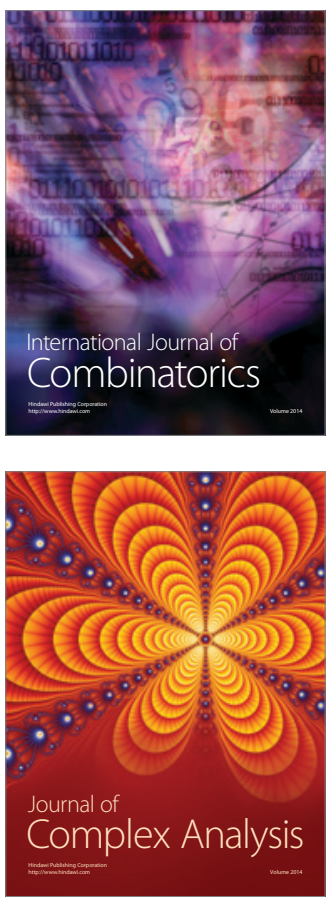

International Journal of

Mathematics and

Mathematical

Sciences
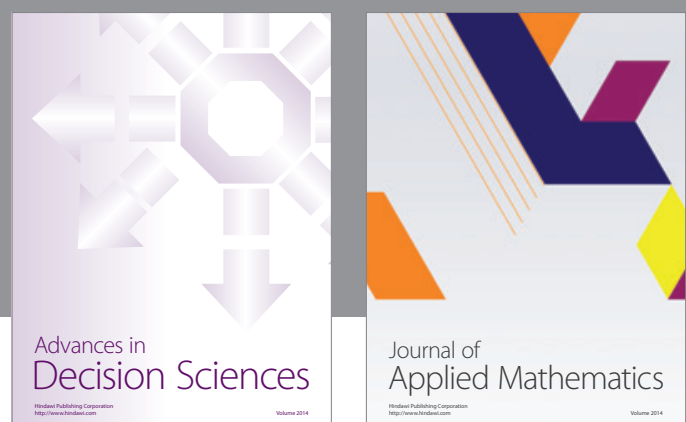

Journal of

Applied Mathematics
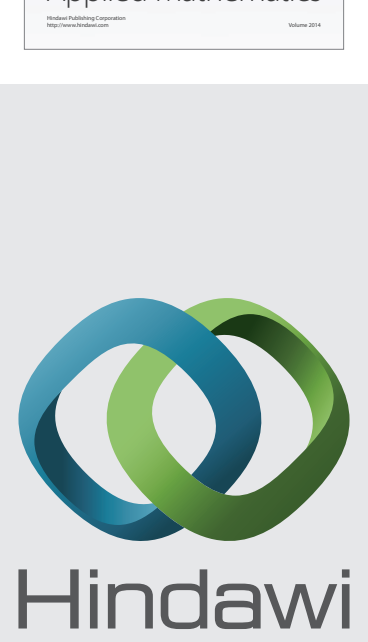

Submit your manuscripts at http://www.hindawi.com
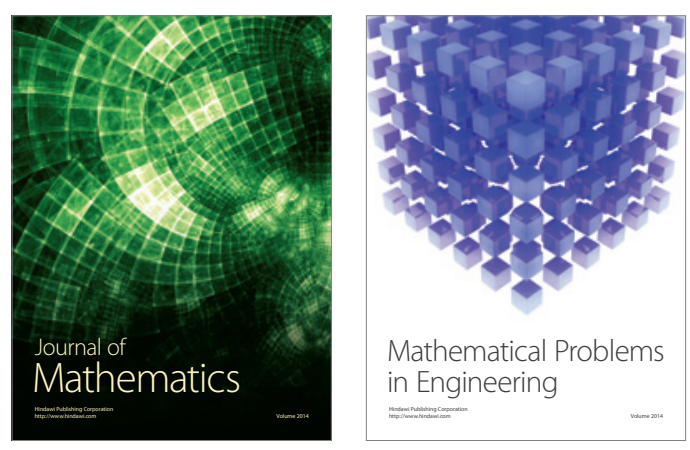

Mathematical Problems in Engineering
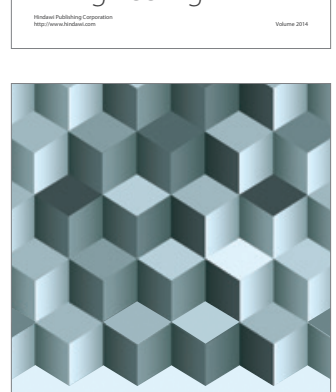

Journal of

Function Spaces
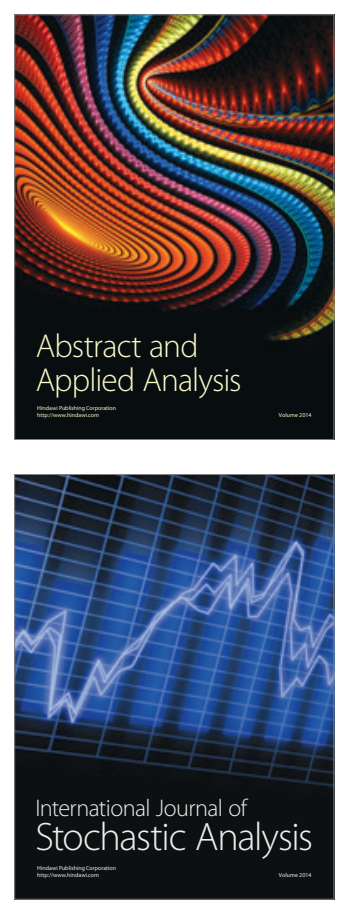

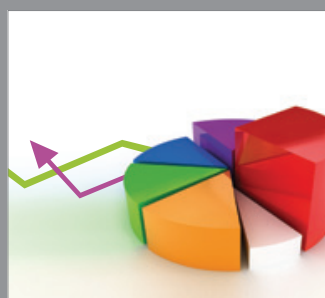

ournal of

Probability and Statistics

Promensencen
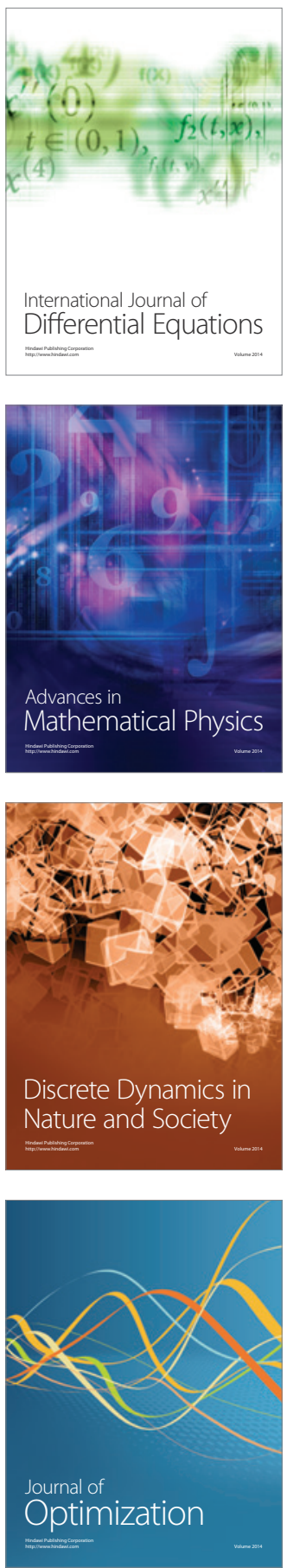